\title{
Incidence and treatment of hand and wrist injuries in Dutch emergency departments
}

\author{
Roderick H. van Leerdam ${ }^{1}$ (D) . Pieta Krijnen ${ }^{1}$. Martien J. Panneman ${ }^{2} \cdot$ Inger B. Schipper $^{1}$
}

Received: 6 August 2020 / Accepted: 11 June 2021 / Published online: 1 July 2021

(c) The Author(s) 2021

\begin{abstract}
Purpose The purpose of this study was to describe the epidemiology, treatment and costs of hand and wrist injuries presenting to the Dutch ED. With increasing medical costs and crowding of emergency departments (ED), a more detailed description of emergency department attendance of hand and wrist injuries and their treatment may help to facilitate more adequate allocation of health care services.

Methods The Dutch Injury Surveillance System obtained a total of 160,250 hand and wrist injuries. Patient characteristics, incidence rates, type of injury, treatment, and costs were described.

Results The incidence of hand and wrist injuries in the Netherlands in 2016 was 11 per 1000 in males and 8 per 1000 in females. This is about $25 \%$ of all injuries presented at the ED. Of all hand injuries, only $3 \%$ was directly admitted to the hospital or received emergency surgery. Thirty percent did not need further treatment in the hospital.

Conclusion The current data suggest that a substantial proportion of the hand and wrist injuries needed no subsequent specialized treatment. Although the severity of the injury could not be deduced from our data, the data suggest a ground for a more extensive role of primary health care (general) practitioners in the primary triage and treatment of hand and wrist injuries. This may reduce health care cost and help decongest the ED departments. Prospective studies are needed to confirm these preliminary conclusions.
\end{abstract}

Level of evidence III.

Keywords Incidence $\cdot$ Hand $\cdot$ Wrist $\cdot$ Emergency department

\section{Introduction}

Injuries of the hand and wrist are among the most common injuries in all age groups and carry the risk of serious handicap [1]. With increasing medical costs and crowding of emergency departments, a more detailed description of emergency department attendance of hand and wrist injuries and their treatment may help to facilitate adequate allocation of healthcare services. Epidemiologic studies about the incidence and management of hand and wrist injuries in the Netherlands are scarce and mostly outdated, or describe only specific subgroups of injuries [2-4].

Roderick H. van Leerdam

r.leerdam@gmail.com

1 Department of Trauma Surgery, Leiden University Medical Center (LUMC), Albinusdreef 2, 2333 ZA Leiden,

The Netherlands

2 Consumer Safety Institute, Amsterdam, The Netherlands
The purpose of this study was to describe the epidemiology and treatment of hand and wrist injuries presented in the Dutch Emergency Departments (ED). Furthermore, we studied the characteristics of these injuries regarding primary treating specialty and costs.

\section{Patients and materials}

\section{Research questions}

This descriptive study aimed to answer the following questions: (1) What are the incidence rates and distribution of different hand and wrist injuries among patients visiting the ED? (2) Can specific groups at risk for these injuries be identified? (3) How are hand and wrist injuries treated and by which specialties? (4) What are the direct medical costs of hand and wrist injuries? 


\section{Study design, data source and study population}

The data for this retrospective cohort study were extracted from the Dutch Injury Surveillance system (DISS). The registry consists of a continuous data collection from 14 Dutch hospital-based emergency departments. These EDs are regarded to be a representative sample for the total number of injured patients presenting at EDs in the Netherlands $[5,6]$. The hospitals consist of three university hospitals, one non-academic teaching hospital and ten general hospitals. The hospitals participating in the DISS serve $13 \%$ of the total Dutch population of 17.02 million (2016). Injuries of all age groups are recorded. For the present study, all records of hand and wrist injuries presenting at the ED in 2016 were collected. These included all injuries to the phalanx, metacarpal, carpal, distal radius, and ulna.

To generate national estimates of hand and wrist injuries, data were extrapolated to the Dutch population. The number of ED visits registered due to hand and wrist injuries by the participating hospitals was multiplied by the quotient of the total number of ED visits in the Netherlands divided by the total number of ED visits registered in the participating hospitals [7].

\section{Data}

Since the data in the DISS are de-identified, no institutional review board approval was required. Registered data included gender, age, and information on diagnosis, treatment, and discharge. Ages of patients were categorized in 5 year age groups.

Age and gender-specific incidence rates were calculated as the ratio of the estimated number of hand/wrist injuryrelated ED visits in the Netherlands and the age and genderspecific population numbers [8].

Causes of injury were recorded according to the International Classification of External Causes of Injuries divided into six categories: home and leisure, sports, occupational, self-mutilation, violence and traffic [5]. Type of injury was divided into three categories: (1) laceration/wound; (2) fractures, and (3) other injuries including sprains, contusions, tendon ruptures, amputations, burns, allergic reactions or not specified types of injuries.

Injury treatment was divided into five categories: no further treatment, referred to general practitioner, conservative/outpatient clinic, emergency operation/admission and unknown. The primary treating specialty was also recorded.

\section{Medical costs}

Direct medical costs as a result of injury to wrist or hand were calculated with the use of the incidence-based Dutch
Burden of Injury Model $[9,10]$. This model calculates healthcare consumption and related costs for predefined injury patient groups that are homogenous in terms of health service use. We included all health services that are relevant for the treatment and rehabilitation of injury patients. Data on injury-related healthcare consumption were obtained from the DISS (ED visits), Hospital Discharge Registry (admissions, duration, procedures), nursing home and home care registers [8] and an injury patient follow-up survey conducted in 2007-2008 [11].

Health care costs of injuries were calculated by multiplying incidence, transition probabilities (e.g. chance of hospital admission, outpatient visit, G.P. care, home care, physical therapy), health care volumes (e.g., length of stay in hospital or institution, the number of outpatient visits, G.P. visits, home care hours, and physical therapy treatments) with unit costs (e.g., costs per day in the hospital, cost per outpatient visit, G.P. visit). All unit costs were estimated according to national guidelines for healthcare costing [12].

\section{Results}

In 2016, 19,324 patients with hand or wrist injuries were treated in the hospitals that participated in the DISS. This number was extrapolated to $160,250 \mathrm{hand} /$ wrist injuries in the Netherlands in 2016.

\section{Incidence}

The number of hand and wrist injuries treated at the EDs in the Netherlands in 2016 was 90,620 in males $(57 \%)$ and 69,630 in females. This is about $25 \%$ of all injuries that present to the ED department. The mean age of the patient population was 33 with a range from 0 to 107 years. Both sides were equally affected (49\% left vs. $47 \%$ right) and bilateral injuries were uncommon (4\%).

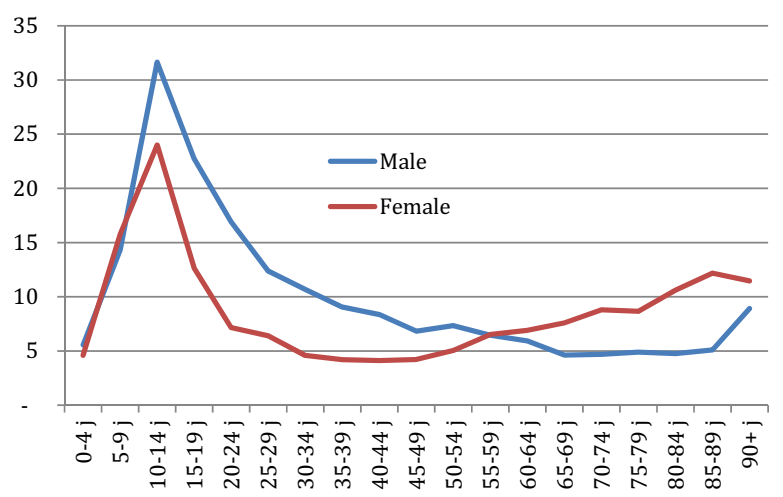

Fig. 1 Incidence of hand and wrist injuries per 1000 inhabitants in the Netherlands in 2016, by sex and age group 
The population incidence rates were $11 / 1000$ in males and 8/1000 in females. Figure 1 shows the incidence per 1000 inhabitants per age group with a peak incidence for injuries in 10-14-year-olds. The incidence in males was higher in the ages below 55 years, while the incidence in the female population was higher after 55 years.

\section{Injury characteristics}

Table 1 shows the incidence and treatment of hand injuries per type of injury. Most patients presented with a fracture (55\%) or a laceration/wound (33\%). Other injuries, such as sprains, burns or contusions, occurred in $12 \%$ of the patients.

Fractures were most often wrist fractures (52\%) followed by finger fractures (32\%).

After initial treatment at the ED, $30 \%$ of all injuries did not need further treatment. Three percent of all hand and wrist injuries were directly admitted or received emergency surgery. Admissions without surgery were rare yet the exact number could not be specified. About half (52\%) of the injuries were caused by home and leisure accidents and about a quarter of these happened during sports activities (24\%).
Occupational, violence or self-mutilation injuries occurred in $14 \%$ and traffic injuries in $10 \%$ of the cases.

Primary treating specialties are summarized in Table 2. The majority of patients with hand and wrist injuries were initially treated by trauma surgeons (56\%) followed by orthopedic surgeons (23\%) and ED physicians (17\%). Plastic surgeons were primarily involved in $2 \%$ of the patients.

\section{Direct medical costs}

The average direct medical costs of hand injuries were calculated to be $€ 1500$ per patient. Based on 160,250 ED visits in 2016, the total health care costs of hand and wrist injuries in the Netherlands were estimated to be $€ 260$ million, which equals $13 \%$ of the total direct medical costs made by patients presenting at Dutch ED departments in 2016 in the Netherlands (2 billion euro) [13]. Mean costs per patient were higher in older ( $>65$ years) men $(€ 2270)$ and women $(€ 3650)$ and the overall mean cost was higher in women $(€ 1900)$ than in men $(€ 1200)$. Fractures

Table 1 Distribution, incidence, and treatment of hand and wrist injuries presented in Dutch emergency departments in 2016, by type of injury

\begin{tabular}{|c|c|c|c|c|c|c|c|}
\hline \multirow[t]{2}{*}{ Injury type } & \multirow{2}{*}{$\begin{array}{l}\text { Incidence } \\
\text { per } 1000\end{array}$} & \multirow{2}{*}{$\begin{array}{l}\text { Injury type of } \\
\text { total }(\%)\end{array}$} & \multicolumn{5}{|l|}{ Treatment } \\
\hline & & & $\begin{array}{l}\text { No further } \\
\text { treatment }(\%)\end{array}$ & $\begin{array}{l}\text { Referred to General } \\
\text { Practitioner }(\%)\end{array}$ & $\begin{array}{l}\text { Conservative/ } \\
\text { Outpatient (\%) }\end{array}$ & $\begin{array}{l}\text { Emergency opera- } \\
\text { tion/Admission (\%) }\end{array}$ & $\begin{array}{l}\text { Unknown } \\
(\%)\end{array}$ \\
\hline Laceration/wound & 3.0 & 33 & 60 & 9 & 23 & 2 & 6 \\
\hline Wrist & 0.6 & 20 & 68 & 7 & 19 & 2 & 5 \\
\hline Carpal/metacarpal & 0.9 & 28 & 64 & 10 & 17 & 3 & 6 \\
\hline Finger & 1.6 & 52 & 55 & 10 & 27 & 2 & 6 \\
\hline Fracture & 5.2 & 55 & 12 & 1 & 82 & 2 & 3 \\
\hline Wrist & 2.7 & 52 & 9 & 0 & 86 & 3 & 2 \\
\hline Carpal/metacarpal & 0.8 & 16 & 11 & 1 & 85 & 1 & 3 \\
\hline Finger & 1.7 & 32 & 17 & 1 & 76 & 1 & 4 \\
\hline Other & 1.2 & 12 & 29 & 3 & 57 & 7 & 5 \\
\hline Wrist & 0.2 & 15 & 45 & 6 & 40 & 5 & 3 \\
\hline Carpal/metacarpal & 0.2 & 14 & 32 & 4 & 48 & 9 & 7 \\
\hline Finger & 0.8 & 71 & 24 & 2 & 62 & 8 & 4 \\
\hline Total & & & 30 & 4 & 60 & 3 & 4 \\
\hline
\end{tabular}

Table 2 Primary treating specialty per type of injury

\begin{tabular}{lcrrlllll}
\hline Primary treating Speciality & Laceration/wound & $\%$ & Fracture & $\%$ & Other & $\%$ & Total & $\%$ \\
\hline Emergency department & 12,941 & 25 & 10,674 & 12 & 3524 & 18 & 27,139 & 17 \\
Trauma surgery & 26,757 & 52 & 53,104 & 60 & 10,468 & 52 & 90,329 & 56 \\
Orthopedics & 9550 & 18 & 22,341 & 25 & 4517 & 23 & 36,408 & 23 \\
Plastic surgery & 1042 & 2 & 317 & 0.4 & 1083 & 5 & 2442 & 2 \\
Unknown / other specialty & 1459 & 3 & 2068 & 2 & 405 & 2 & 3932 & 2 \\
Total & 51,749 & 100 & 88,504 & 100 & 19,997 & 100 & 160,250 & 100 \\
\hline
\end{tabular}


accounted for more than two-third ( $€ 172$ million) of the total costs of hand injuries.

\section{Discussion}

The main findings of this exploratory descriptive analysis are that most hand and wrist injuries presented at the ED are fractures, followed by lacerations and wounds. Children in the age group 10-14 years are at higher risk to sustain a hand or wrist injury. Thirty percent of the hand and wrist injuries do not need subsequent treatment or followup, whereas emergency admission or surgery is needed in only $3 \%$. At the ED, the trauma surgeons predominantly provide the primary care for hand and wrist injuries. The majority of costs are due to fractures of the hand and wrist in patients of 55 years of age and older.

The calculated incidence of hand and wrist injuries was $19 / 1000$ in the Netherlands in 2016 . This number does not seem to change over time since the incidence in 2004 was calculated to be 18 per 1000 for the Netherlands by Larsen et al. [3]. The Dutch incidence falls within the incidence range of that in other European countries, which is estimated to be $15-38$ per 1000 [3,14-16]. The age-related peak rates of injury are similar to that found in other studies $[15,17,18]$. Previous studies show that the proportion of hand and wrist injuries out of all accidental injuries treated at the ED varies between 14 and 27\% [19-21]. The numbers in the Netherlands fall within this range $(25 \%$ on average) but can be considered relatively high.

Although injuries of the hand and wrist are common, only $3 \%$ of these injuries were directly admitted or treated surgically (emergency admission/surgery). This is concordant with previous literature [3, 16, 21]. Remarkably, $30 \%$ of all injuries, including $60 \%$ of the wounds and lacerations, did not need further treatment after initial treatment at the ED. This may imply that a general practitioner could probably have triaged and treated a subset of these patients. A shift of primary presentation from the hospital to primary health care could result in a considerable cost reduction, along with reduction of ED overcrowding and workload, and subsequent reduced ED waiting times. General practitioners are available during daytime and take shifts during the evening and night. Self-referral to the ED during these hours is common. In the Netherlands, out of hours primary care is increasingly provided by general practitioner cooperatives (GPC) and arose from the need to decrease the overcrowding of the ED. GPCs are usually situated in or near a hospital, sometimes sharing triage and diagnostic resources of the hospital. One of the objectives is to treat and triage more "self-referrals" otherwise presenting to the ED, decreasing emergency department use up to $22 \%$ [22]. The care for these patients at the GPC could be up to three times cheaper than in the ED [23].

The risk of missed diagnoses by the GP decreases when a GP has proper access to diagnostic facilities [24]. Given the increase of general practitioner cooperatives situated in or near a hospital, we expect this risk to be acceptable.

The fact that hand and wrist injuries comprise $25 \%$ of the injuries presented at the ED, $30 \%$ needed no further treatment combined with the finding that the majority are treated by trauma surgeons and ED physicians, but not by plastic surgeons, implies that many wounds did not require specialized care and were probably of minor severity. This is another good reason for reallocation of patients and care to the primary health care providers, in an attempt to optimize the quality of care and costs balance.

According to this study, hand injuries accounted for $€ 260$ million of direct medical costs. Hence, hand injuries constitute not only a substantial part of all injuries at the ED but also represent a considerable economic burden to society. Estimates of the economic costs of different acute hand and wrist injuries vary greatly depending on the study methodology, however, by any standards, these injuries should be considered a substantial burden on the individual and society [25]. The total costs are expected to be even higher if productivity loss due to work absenteeism is included in the calculation on top of the direct medical costs. In our opinion, accurate prevention starts by a deep understanding of the problem. Accurate data on these injuries is an essential starting point.

The strengths of this study include the fact that this study gives a renewed and detailed nationwide overview of all hand and wrist injuries presenting at the ED. In contrast to other studies, this study also takes costs into account and describes treatments.

The results also should be interpreted in light of their shortcomings. First, the data are from 2016, and more recent data were not available for analysis. However, but we do not expect that more recent data would change the results and conclusions of the study, since demographics and outcome have not changed, and since there have not been any policy changes of influence in our health care system during the past four years. Furthermore, although the DISS has proven to be a good tool to identify injuries at the ED [18, 26-29], the database uses estimates for incidence rates which may have led to inaccurate results. Also, the DISS registry does not include data explaining why a patient is admitted or if he is (self)-referred. Unfortunately, the database included only records on hand and wrist injuries presented at the ED. This underestimates the true nationwide incidence of hand and wrist injuries, since minor injuries are often presented to and treated by the general practitioner in the Netherlands. Also, patients that are treated in hospital in a planned fashion were not included in our study. Another limitation is that the 
database fails to register changes in diagnosis after the ED visit. This was also a shortcoming described by Beerekamp et al. [30], possibly causing an over- or underestimation of certain specific hand and wrist injuries. Finally, this study only estimated the direct medical costs including all health services.

In our opinion, this study provides an accurate overview of hand and wrist injuries treated at the EDs in the Netherlands. Given the crowding of the ED departments, the current data suggests that a substantial proportion of the hand and wrist injuries needed no subsequent specialized treatment. Although the severity of the injury could not be deduced from our data, the data suggest a ground for a more extensive role of primary health care (general) practitioners in the primary triage and treatment of hand and wrist injuries, provided that general practitioners are sufficiently equipped with additional education, diagnostic facilities and surgical expertise. This may reduce health care cost and help decongest the ED departments. Prospective studies are needed to confirm these preliminary conclusions.

Authors' contributions RL designed the study and wrote manuscript. PK and IS drafted the manuscript and helped interpret data. MP collected and analyzed the data. He also helped draft the manuscript.

Funding The author(s) received no financial support for the research, authorship, and/or publication of this article.

Availability of data and material The data that support the findings of this study are available from the Dutch Injury Surveillance system (DISS). Restrictions apply to the availability of these data, which were used under license for this study. Data are available Martien Pannenman with the permission of DISS.

Code availability All code for data cleaning and analysis associated with the current submission is available through Martien Pannenman.

\section{Declarations}

Conflict of interest The author(s) declare no potential conflicts of interest with respect to the research, authorship, and/or publication of this article.

Ethical approval Ethical approval was not sought for the present study because all de-identified data was received from a national registry. This study was completed in accordance with the Helsinki Declaration as revised in 2013 .

Consent to participate Not applicable.

Consent for publication Not applicable.

Open Access This article is licensed under a Creative Commons Attribution 4.0 International License, which permits use, sharing, adaptation, distribution and reproduction in any medium or format, as long as you give appropriate credit to the original author(s) and the source, provide a link to the Creative Commons licence, and indicate if changes were made. The images or other third party material in this article are included in the article's Creative Commons licence, unless indicated otherwise in a credit line to the material. If material is not included in the article's Creative Commons licence and your intended use is not permitted by statutory regulation or exceeds the permitted use, you will need to obtain permission directly from the copyright holder. To view a copy of this licence, visit http://creativecommons.org/licenses/by/4.0/.

\section{References}

1. Ootes D, Lambers KT, Ring DC. The epidemiology of upper extremity injuries presenting to the emergency department in the United States. Hand (N Y). 2012;7(1):18-22. https://doi.org/10. 1007/s11552-011-9383-z.

2. de Putter CE, van Beeck EF, Looman CW, Toet H, Hovius SE, Selles RW. Trends in wrist fractures in children and adolescents, 1997-2009. J Hand Surg. 2011;36(11):1810-1815e2. https://doi. org/10.1016/j.jhsa.2011.08.006.

3. Larsen CF, Mulder S, Johansen AM, Stam C. The epidemiology of hand injuries in The Netherlands and Denmark. Eur J Epidemiol. 2004;19(4):323-7.

4. Orces CH, Martinez FJ. Epidemiology of fall related forearm and wrist fractures among adults treated in US hospital emergency departments. Inj Prev. 2011;17(1):33-6. https://doi.org/10.1136/ ip.2010.026799.

5. Meerding WJ, Polinder S, Lyons RA, Petridou ET, Toet H, van Beeck F, et al. How adequate are emergency department home and leisure injury surveillance systems for cross-country comparisons in Europe? Int J Inj Contr Saf Promot. 2010;17(1):13-22. https:// doi.org/10.1080/17457300903523237.

6. Panneman M, Blatter B. Letsel Informatie Systeem; Representatief voor alle SEH's in Nederland? VeiligheidNL. 2016. Accessed 5 Mar 2019

7. Gaakeer MI, van den Brand CL, Veugelers R, Patka P. Inventory of attendance at Dutch emergency departments and self-referrals. Ned Tijdschr Geneeskd. 2014;158:A7128.

8. Centraal Bureau voor Statistiek. Statline: Bevolking kerncijfers. 2018. https://opendata.cbs.nl/statline/\#/CBS/nl/dataset/37296ned/ table?ts=1528716150231. Accessed 11 June 2018

9. Meerding WJ, Mulder S, van Beeck EF. Incidence and costs of injuries in The Netherlands. Eur J Public Health. 2006;16(3):2728. https://doi.org/10.1093/eurpub/ck1006.

10. Mulder S, Meerding WJ, Van Beeck EF. Setting priorities in injury prevention: the application of an incidence based cost model. Inj Prev. 2002;8(1):74-8.

11. Polinder S, Haagsma J, Panneman M, Scholten A, Brugmans M, Van Beeck E. The economic burden of injury: health care and productivity costs of injuries in the Netherlands. Accid Anal Prev. 2016;93:92-100. https://doi.org/10.1016/j.aap.2016.04.003.

12. Oostenbrink JB, Koopmanschap MA, Rutten FF. Standardisation of costs: the Dutch manual for costing in economic evaluations. Pharmacoeconomics. 2002;20(7):443-54.

13. Stam C, Blatter B. Letsel 2017: Kerncijfers LIS. 2017. https:// www.veiligheid.nl/.ibmmodres/domino/OpenAttachment/Veili gheid/Website.nsf/FD80D963DD249926C125838C003DF481/ asset/Kerncijfers\%20Letsels\%202017.pdf.

14. Elberg JJ, Jorgensen HR, Larsen CF. Hand injuries. Epidemiology, medical and economic consequences. Ugeskr Laeger. 1987;149(16):1096-9.

15. Burke FD, Dias JJ, Lunn PG, Bradley M. Providing care for hand disorders: trauma and elective. The Derby Hand Unit experience (1989-1990). J Hand Surg. 1991;16(1):13-8.

16. Angermann P, Lohmann M. Injuries to the hand and wrist. A study of 50,272 injuries. J Hand Surg. 1993;18(5):642-4. 
17. Giustini M, de Leo A, Leti Acciaro A, Pajardi G, Mamo C, Voller $\mathrm{F}$, et al. Incidence estimates of hand and upper extremity injuries in Italy. Ann Ist Super Sanita. 2015;51(4):305-12. https://doi.org/ 10.4415/ANN_15_04_10.

18. de Putter CE, Selles RW, Polinder S, Hartholt KA, Looman CW, Panneman MJ, et al. Epidemiology and health-care utilisation of wrist fractures in older adults in The Netherlands, 1997-2009. Injury. 2013;44(4):421-6. https://doi.org/10.1016/j.injury. 2012. 10.025 .

19. Campbell AS. Hand injuries at leisure. J Hand Surg. 1985;10(3):300-2.

20. Oostrom CA, Houpt P. Fifty years of plastic surgery in the Netherlands. I. Seemingly minor accidents: major hand injuries. Ned Tijdschr Geneeskd. 2000;144(21):961-5.

21. Smith ME, Auchincloss JM, Ali MS. Causes and consequences of hand injury. J Hand Surg. 1985;10(3):288-92.

22. Smits M, Rutten M, Keizer E, Wensing M, Westert G, Giesen P. The development and performance of after-hours primary care in the Netherlands: a narrative review. Ann Intern Med. 2017;166(10):737-42. https://doi.org/10.7326/M16-2776.

23. Rutten M. Thesis: acute primary care in the Netherlands: the collaboration between general practitioner cooperatives and emergency departments. Nijmegen: Radboud University; 2019.

24. Jacobs JJ, Jacobs JP, van Sonderen E, van der Molen T, Sanderman R. Fracture diagnostics, unnecessary travel and treatment: a comparative study before and after the introduction of teleradiology in a remote general practice. BMC Fam Pract. 2015;16:53. https://doi.org/10.1186/s12875-015-0268-z.
25. Robinson LS, Sarkies M, Brown T, O'Brien L. Direct, indirect and intangible costs of acute hand and wrist injuries: a systematic review. Injury. 2016;47(12):2614-26. https://doi.org/10.1016/j. injury.2016.09.041.

26. Oudshoorn C, Hartholt KA, Zillikens MC, Panneman MJ, van der Velde N, Colin EM, et al. Emergency department visits due to vertebral fractures in the Netherlands, 1986-2008: steep increase in the oldest old, strong association with falls. Injury. 2012;43(4):458-61. https://doi.org/10.1016/j.injury.2011.09.014.

27. Scholten AC, Polinder S, Panneman MJ, van Beeck EF, Haagsma JA. Incidence and costs of bicycle-related traumatic brain injuries in the Netherlands. Accid Anal Prev. 2015;81:51-60. https://doi. org/10.1016/j.aap.2015.04.022.

28. Ten Brinke JG, Saltzherr TP, Panneman MJM, Hogervorst M, Goslings JC. Incidence of spinal fractures in the Netherlands 1997-2012. J Clin Orthop Trauma. 2017;8(Suppl 2):S67-70. https://doi.org/10.1016/j.jcot.2017.03.011.

29. van Beeck EF, Panneman MJM, Polinder S, Blatter B. Injuries resulting from accidents and violence in the Netherlands; results of an Emergency Department register. Ned Tijdschr Geneeskd. 2017;161:D1534.

30. Beerekamp MSH, de Muinck Keizer RJO, Schep NWL, Ubbink DT, Panneman MJM, Goslings JC. Epidemiology of extremity fractures in the Netherlands. Injury. 2017;48(7):1355-62. https:// doi.org/10.1016/j.injury.2017.04.047. 